\title{
artículos
}

\section{Sociedad civil y estado en Hegel: prolegómeno indispensable para la crítica marxista de la sociedad burguesa ${ }^{\star}$}

Civil Society and State in Hegel: an Indispensable Prologue to the Marxist

Critique of Bourgeois Society

\section{GONZALO GALLARDO BLANCO}

Universidad Autónoma de Madrid https://doi.org/10.15366/antitesis2021.2.004 
Recibido: $21 / 07 / 21$

Aceptado: 26/11/21

Resumen: En el presente trabajo se pretende llevar a cabo una aproximación a la filosofía política hegeliana centrada en la sociedad civil y el estado, como dos de los momentos más importantes de este estadio de su filosofía, estudiando su relación con la posterior crítica marxista de la sociedad burguesa. De este modo, se intentará mostrar que Hegel no puede alcanzar a comprender dicha sociedad burguesa en su totalidad ya que sólo tras el desarrollo completo de la sustancia -el modo de producción capitalista- puede comprenderse su forma al completo. Y que ello, no obstante, no resta un ápice de radicalidad y cariz revolucionario a muchos postulados de Hegel en este ámbito.

Palabras clave: Hegel; Marx; sociedad civil; estado; universal.

Abstract: In the present paper we intend to carry out an approach to Hegel's political philosophy focused on the society and the state, as two of the most important moments of this part of his philosophy, studying their relationship with the later Marxist critique of bourgeois society. In this way, it will try to show that Hegel is unable to understand this bourgeois society in its entirety, since only after the complete development of the substance -the capitalist mode of production- can its form be fully understood. And this does not, however, reduce nothing of the radicality and revolutionary character of many of Hegel's postulates in this area.

Keywords: Hegel; Marx; civil society; state; universal. 


\section{Introducción}

T a obra filosófica de Hegel es una de las aportaciones más espectaculares de Lla historia de la filosofía. Debido a su sistematicidad, la cual cabe señalarse no es absoluta y cerrada, son muchísimos los ámbitos de nuestra realidad en la que esta se sumerge. En este pequeño ensayo intentaremos centrarnos en el ámbito de su filosofía política, que a continuación trataremos de situar brevemente en el conjunto de su sistema, prestando especial atención al lugar de la sociedad civil y el estado en ella ${ }^{1}$. Lo haremos a partir de sus Principios de la Filosafia del Derecho (1821), obra fundamental para el tema que nos ocupa, y a través de la cual expondremos los principales rasgos con los que Hegel presenta estas dos categorías tan importantes para toda la filosofía política posterior.

No obstante, cabe confesar que la intención del trabajo será doble, pues al mismo tiempo que se presentan los rasgos fundamentales de esta parte del sistema hegeliano, estos serán puestos en diálogo con otra de las elaboraciones filosóficas más importantes de nuestra historia, la teoría crítica marxista. En este sentido, la hipótesis del trabajo consiste en que las conclusiones a las que llegará Hegel respecto a la sociedad civil y el estado, en una exposición crítica

1 Cabe señalar, a modo de indicación preliminar, que a lo largo de todo el escrito el término «estado» será incorporado en minúsculas debido a una decisión estrictamente política, pues creo que la concreta utilización de ciertos significantes sirve para constituir sus significados y que, estando en este caso ante una forma política histórica y, por tanto, superable y transitoria (ahí la decisión política), no procede en absoluto su incorporación en mayúsculas, que en la lengua española puede contribuir a su magnificación y eternización. Además, lo hago en continuidad con Juan Luis Vermal, traductor de la edición de los Principios de la Filosofía del derecho que en este escrito vamos a seguir, el cual emplea el término de la misma forma. Las alusiones al término incorporadas por otros autores serán, no obstante, respetadas en su literalidad, de tal modo que en el escrito habrá también ocasiones en las que este se utilice en mayúsculas. 
sumamente elaborada y totalmente alejada de ningún tipo de apología de ningún estado reaccionario - como el prusiano-, constituyen un prolegómeno indispensable para el surgimiento de la crítica de Marx de la sociedad burguesa.

\section{Una pequeña aproximación al sistema hegeliano en su conjunto}

Como sabemos, el sistema filosófico hegeliano puede dividirse - siguiendo su orden enciclopédico- en tres grandes partes: la lógica, ciencia del pensar y sus determinaciones; la filosofia de la naturaleza, en cuyo estudio se insertan la mecánica, la física y la física orgánica; y la filosofia del espíritu, estudio de la verdad y el saber filosófico. Como señala Aragüés, las últimas dos partes no son reductibles a la primera, por mucho que esta las fundamente, dado que reflexionan a partir de «un material aportado por la experiencia, por las ciencias naturales y sociales y los acontecimientos históricos y políticos, un material que no es el producto del desarrollo puro y a priori del pensar como sí lo es el contenido de la lógica especulativa, pero que es tremendamente relevante para la filosofía real» ${ }^{2}$. Pues bien, será en esta filosofía real en la que trataremos de adentrarnos en este ensayo, a partir del tratamiento de una pequeña parte de su filosofia del espiritu, a la que generalmente se conoce como filosofia del derecho, en la cual encontraremos lo más parecido posible a una especie de «filosofia política hegeliana».

Así pues, como punto de partida, cabe comenzar aclarando que, dentro de su filosofía del espíritu, la filosofía del derecho corresponde al espíritu objetivo, superior al espíritu subjetivo (del que son parte antropología, fenomenología y psicología) e inferior al espíritu absoluto (donde se situarían el arte, la religión y la filosofía). En sus Principios de la Filosofia del Derecho, obra en la que tratará Hegel de sistematizar el estudio de este espíritu objetivo, familia, sociedad civil y estado se presentarán como las partes más importantes de dicho estadio $^{3}$. Estos se abordarán en la tercera parte de la obra, correspondiente a «la eticidad», a la cual se llega tras el tránsito por «el derecho abstracto» y «la moralidad», esto es, los dos elementos restantes que conformarán la triada del espíritu objetivo. De esa forma, será en la eticidad donde verdaderamente se producirá la realización de la idea del bien, que trasciende el ámbito de la voluntad y se realiza también en el mundo externo, formado por estructuras político-sociales ${ }^{4}$. Así, sostiene Hegel, es aquí, a través de sus diversos momentos,

2 ARAGÜÉS, R., Introducción a la Lógica de Hegel, Herder, Barcelona, 2021, p. 317.

3 Cabe señalar que, además de en esta obra, Hegel tratará ya muchos de estos temas en algunos escritos anteriores como La constitución de Alemania (1801-1802), sus cursos de Derecho natural y Ciencia del Estado (1818-19) y, claro está, en su Enciclopedia de las Ciencias Filosóficas (1817), la gran obra sintetizadora de su sistema.

4 DUQUE, F., Historia de la Filosofía Moderna: La Era de la Crítica, Ed. Akal S.A., Madrid., 1998, p. 811. 
donde «alcanza el concepto realidad y es por lo tanto como idea, es decir, como concepto que ha llevado sus determinaciones a la realidad y al mismo tiempo, en su identidad, es su esencia existente en sí», es decir, donde «el concepto de la libertad deviene mundo existente» $(\S 141 \text {, Obs. y } \S 142)^{5}$. Dicha existencia en sí, dicho alcanzar la realidad, se manifestará de este modo precisamente en las estructuras e instituciones que conformarán familia, sociedad civil y estado, en las cuales vamos a centrarnos.

\section{La sociedad civil en Hegel: de intereses diversos a intereses antagónicos}

La sociedad civil hegeliana surge a partir la familia. Esta constituye en Hegel el «reino animal del espíritu objetivo» ${ }^{6}$, el primer momento de la eticidad, la «sustancialidad inmediata del espíritu» $(\S 158)^{7}$. La familia, no obstante, se dota de diversas instituciones como el matrimonio, la conformación del patrimonio familiar, la educación y la herencia, a través de las cuales queda purificada de su inmediatez, de su animalidad. Ahora bien, tras ello, se producirá precisamente su disolución, la cual se genera «de manera natural y esencialmente por el principio de personalidad» $(\S 181)^{8}$, uno de los principios rectores de la sociedad civil, a través de la emancipación de los hijos y la creación de su propia familia, todo lo cual da lugar a la sociedad civil, de la que los individuos formarán parte ya específicamente como tal, es decir, como partes de una universalidad formal, fuera de la unidad constitutiva y constituyente de la familia.

Esta universalidad formal de la sociedad civil se conformará así por medio de sus necesidades, cuyo intento de satisfacción une, en cuanto ya considerados como miembros, a individuos independientes, dado que la particularidad de cada persona concreta está en relación con la particularidad de la del resto, «de manera tal que sólo se hace valer y se satisface por medio de

5 HEGEL, G. W. F., Principios de la Filosofía del Derecho (trad. Juan Luis Vermal), Edhasa Ed., Barcelona, 1988, p. 222 y 227. Porque recuérdese que la idea, lejos de las vulgarizaciones con las que se la ha presentado tantas veces, constituye y significa la unidad y compenetración del concepto y su realidad (encarnación esta de la formulación subjetiva de aquel), cuya realización será precisamente el espíritu. Así, como afirma Aragüés, la congruencia entre concepto y objetividad no se genera «mediante la aserción de que el concepto concuerda necesariamente con una realidad que lo expone, sino gracias a que la Lógica muestra efectivamente que a la estructura ideal del concepto le corresponde una realidad concreta y, por tanto, una objetividad». Con ello el concepto alcanza congruencia consigo mismo, es decir, tenemos al concepto en su idealidad. Y este concepto adecuado es la Idea (Aragüés, R., Introducción a la Lógica, op. cit., p. 270).

6 DUQUE, F., Historia de la Filosofía Moderna..., op. cit., p. 822.

7 HEGEL, G. W. F., Principios de la Filosofía del Derecho..., op. cit., p. 237.

8 Ibid., p. 258. 
la otra y a la vez sólo por la mediación de la forma de la universalidad» $(\$ 182)^{9}$. Dicha forma constituirá así para Hegel uno de los dos principios rectores de la sociedad civil, sumado al de personalidad independiente, por el cual la persona concreta se presenta como totalidad de necesidades, mezcla de algunas naturales y otras arbitrarias $(\S 182)^{10}$. En abierta crítica al atomismo individualista de la mayor parte del liberalismo de la época, entenderá Hegel que la sociedad civil se configurará como un «sistema de dependencia multilateral», en el que pese a que cada uno es fin para sí mismo, siendo el resto «medios para el fin del individuo particular», el fin particular solo se satisface en relación con el resto de fines particulares en la forma de la universalidad, es decir, solo «se satisface al satisfacer al mismo tiempo el bienestar de los demás» $(\S 182, \text { Agr. })^{11}$, bienestar en el cual se fundamenta.

Pues bien, dicha sociedad civil contiene tres momentos. El primero lo conformará su sistema de necesidades, al que da lugar el intento de satisfacción de estas por parte de los individuos, en el que resultarán esenciales los distintos modos y medios con los que se tratarán de satisfacer dichas necesidades (ya que quedan todos - necesidades, modos y medios- como «algo concreto, en cuanto social» en cuya medida «todo lo particular deviene social» [\$192 y Agr. $]^{12}$ ). Este modo de la necesidady la satisfacción conduce, por tanto, al modo del trabajo, caracterizado como la verdadera mediación que genera los medios adecuados para el cumplimiento de dichas necesidades, especificando «el material inmediatamente proporcionado por la naturaleza» $(\S 196)^{13}$. Y dicho modo conlleva de esta manera la división social del trabajo, porque «la abstracción que ocasiona la especificación de los medios y las necesidades» implica también la especificación de su producción, tratando de hacerlo cada vez más simple, y generando mayores

9 Ibid., p. 260. Cabe mencionar que su afirmación en el agregado de dicho parágrafo de que «puesto que la particularidad está ligada a la condición de la universalidad, la totalidad es el terreno de la mediación. En ella se libera toda individualidad», lejos de ser una mera aclaración sobre el tema que nos ocupa, que lo es, constituye también una lección esencial para la praxis política y el intento de rearticulación de un sujeto revolucionario para nuestro siglo, en un momento en que el tema de las identidades (particulares) y su relación con el movimiento obrero (universal) ha ganado gran relevancia en el debate público.

10 Ídem.

11 Ídem. Este punto, crucial a mi parecer para entender la filosofía política de Hegel, será de nuevo de vital importancia al abordar el estado, donde tal juego entre particularidad y universalidad, entre intereses individuales y bienestar general, tendrá una relevancia política de primerísimo orden.

12 Ibid., p. 270. Apunte ciertamente novedoso y esencial para toda la tradición marxista del siglo XIX, que convertirá la «praxis social» en su verdadero objeto de análisis precisamente desde este prisma.

13 Ibid., op. cit., p. 272. Intento de satisfacción de necesidades que, como señalará en este punto mejor la Enciclopedia (\$533), la sociedad no asume de manera consciente, sino mecánica, en el sentido de que las necesidades sólo se cubren para algunas personas (no para todas) y no siempre, de tal forma que dicha contingencia es casi aleatoria (HEGEL, G. W. F., Enciclopedia de las ciencias [Ed., Valls Plana], Alianza Editorial, Madrid, 2005, p. 550). 
cantidades, lo que refuerza a su vez la «dependencia y relación reciproca de los hombres» en el intento de su satisfacción $(\$ 198)^{14}$.

Así, estos modos, debido a la dependencia y reciprocidad que incorporan para los miembros de la sociedad civil en la búsqueda de satisfacción de sus necesidades a través del trabajo, hacen que cada uno de sus integrantes participe en el patrimonio general y permanente de la sociedad $(\S 199)^{15}$, con su concreta participación en aquel postulado entonces como su patrimonio particular. Y aquí llegamos a un punto muy interesante de la filosofía política hegeliana, porque para Hegel éste es necesariamente (o, dicho de otra forma, naturalmente) desigual en los distintos miembros de la sociedad, debido a la desigual distribución de condiciones corporales y espirituales que se produce de manera natural, y debido también a las distintas habilidades a las que estas dan lugar. De esta forma, la «necesaria desigualdad de los patrimonios», que corresponde a la «la desigualdad de los hombres puesta por la naturaleza» (\$200 y Obs.) ${ }^{16}$, dará lugar a una sociedad civil dividida en clases, para Hegel «grupos generales» que adoptan diversos «sistemas particulares de necesidades, medios y trabajo, de modos de satisfacción y de cultura teórica y práctica» en los que divide la totalidad social $(\$ 201)^{17}$. Las clases en las que se dividirá dicha sociedad civil serán así tres: I. la clase agrícola, «sustancial o inmediata»; II. la clase industrial, «formal o reflexiva» (artesanos, trabajadores fabriles y comerciantes); y III. el funcionariado, «clase universal» ocupada de los intereses generales $(\$ 202-205)^{18}$.

Pues bien, dichas clases constituirán para Hegel, tras la familia, la segunda base del estado: serán ellas las que lograrán «ligar el egoísmo [natural para Hegel en todo individuo] al estado», cuya preocupación debe pasar a convertirse entonces en intentar que el «conjunto [de esa sociedad civil dividida en clases] sea sólido y firme» (\$201, Agr. $)^{19}$. Aquí, por tanto, presenta Hegel claramente su concepción de la relación entre estado y sociedad civil, pues como las clases que componen dicha sociedad civil son una de las bases del estado, y

14 HEGEL, G. W. F., Principios de la Filosofía del Derecho.., op. cit., p. 273.

15 Ibid., p. 274.

16 Ídem.

17 Ibid., p. 275. A dicha «división» en clases de la sociedad civil la llamará luego Marx, con mucha razón creemos aquí, «escisión». Lo cierto es que cuesta poco darse cuenta de la tremenda influencia que tuvo esta parte del sistema hegeliano en la teoría social marxista, donde las clases se configuran como tal precisamente por su relación respecto a los medios de producción necesarios para la reproducción social, totalmente equivalentes a lo que Hegel estaría llamando aquí «sistemas particulares de necesidades, medios y trabajo».

18 Ibid., p. 275-278. Como señala Juan Luis Vermal, traductor de la edición con la que estamos trabajando, «clase» y «estamento», los dos términos en castellano utilizados para traducir el término «Stand» empleado por Hegel, están estrechamente ligados en la teoría de este, de tal forma que tiene sentido usar «clase» cuando nos movemos en el ámbito social y «estamento» cuando lo hacemos en el político-representativo (p. 275, nota al §261).

19 Ibid., p. 275. 
dado que dicha división en clases se produce de forma natural, el estado tiene, así, en cuanto objetivo, servir de cohesionador entre dichas clases, de modo tal que el conjunto de dicha sociedad civil sea sólido. Ahora bien, pensando en términos dialécticos, para que tal función cohesionadora pueda llevarse a cabo por parte del estado, es decir, para que a este le sea lógicamente posible desarrollar dicha tarea, es necesario que estas clases no posean intereses antagónicos, esto es, completamente enfrentados e irreconciliables (en cuyo caso no cabría cohesión ni conciliación alguna posible sino solamente una nueva disolución, un nuevo salto hacia adelante en su sistema). Más bien se trata de que, ante cualquier tipo de caso, estemos frente a intereses distintos entre dichas clases.

Esto es lo que creemos que ocurre precisamente en Hegel, para el cual los intereses de dichas clases pueden ser distintos debido a la particularidad subjetiva que deviene objetiva en ellas, pero no antagónicos, dado que, en ese caso, sería lógicamente imposible que este entendiera que tal particularidad, tales intereses distintos, pudieran constituir un «principio vivificante de la sociedad civil, del desarrollo de la actividad pensante, del mérito y del honor» (\$206, Obs.) $)^{20}$. Así, pensamos que Hegel, dado el incipiente desarrollo de las características de la sociedad burguesa presentes en el momento en el que escribe, es aun -lógicamente- incapaz de vislumbrar tal antagonismo. $\mathrm{Y}$ es que, como sabemos, hasta que la sustancia no se desarrolla al completo es imposible que su forma sea totalmente visible. Por ello, dado el incipiente desarrollo del modo de producción capitalista y el escaso despliegue de la sociedad burguesa a la que este estaría dando lugar, Hegel no podía (y tampoco tenía que, cabría decir, aunque esa es otra cuestión) haber llegado a tales conclusiones $^{21}$. En este sentido, la crítica marxista aparece entonces de forma aún más clara como continuadora, como desarrollo lógico y necesario, de la filosofía hegeliana, dado que Marx, ya sí, tras los años de desarrollo productivo y social de las décadas que conforman el grueso del siglo XIX, será quien podrá encontrar dicha sustancia desarrollada al completo, lo que le permitirá ser

20 Ibid., p. 279. Otra prueba que creemos puede avalar esta tesis es la afirmación de Hegel, al tratar del poder de la policía («de la organización y reglamentación interna de un estado»), de que: «Los diversos intereses de productores y consumidores pueden entrar en conflicto entre sí, y si bien en el todo la relación correcta se produce por sí misma, la compensación requiere una regulación consciente que esté por encima de ambas partes» (\$236, p. 304, [el subrayado es mío]). Como puede observarse, por un lado, habla aquí Hegel explícitamente de diversos intereses, es decir, de intereses diferenciados entre diferentes clases o grupos, pero no de intereses antagónicos. Por otro lado, afirma que dichos intereses pueden entrar en conflicto entre sí, lo que supone que no necesariamente tengan que hacerlo siempre.

21 Como afirmará Lukács tratando los puntos de quiebra entre Hegel y Marx: «Hegel no consiguió llegar hasta las verdaderas fuerzas motoras de la historia. En parte porque en la época de la constitución de ese sistema dichas fuerzas no estaban aún visibles de modo suficientemente claro» (LUKÁCS, G., Historia y consciencia de clase - Vol. I, Ediciones Orbis, Barcelona, 1985, p. 77). Una tesis similar puede explorarse en: BLUNDEN, A., Hegel for Social Movements, Brill, Leiden, 2019. 
consciente de su verdadera forma: una sociedad escindida en clases con intereses antagónicos e irreconciliables ${ }^{22}$.

No parece entonces acertado el intento de hacer pasar a Hegel, respecto de su filosofía política, como un ideólogo burgués, como un mero arquitecto o apologeta de la sociedad burguesa, por la cual estaría justificando todos los distintos males sociales a los que estaba dando lugar, ni mucho menos como un reaccionario. Muy alejado de esto, la exposición hegeliana de la sociedad civil en sus Principios de la Filosofía del Derecho puede leerse como una elaboración crítica sumamente brillante de la sociedad de su época, que incorpora elementos imprescindibles para toda la tradición revolucionaria posterior a este, pero que, como es lógico, no puede llegar aún a dichos postulados revolucionarios, precisamente porque la filosofia no puede ir más allá de su propio tiempo ${ }^{23}$. Así, como hasta conservadores de la talla de Carl Schmitt han logrado ver, aparte de todos sus servicios en la política del día a día, «la filosofía y el método dialéctico de Hegel no permitían estancamiento ni reposo, y, en ese respecto, era y seguía siendo la pieza más revolucionaria que la humanidad había producido» ${ }^{24}$. Y es que, en este sentido, debe reconocerse que, pese a que Hegel no llega a vislumbrar la escisión de una sociedad en clases con intereses antagónicos, sí llegará, sin embargo, a admitir explícitamente la lucha de clases (con intereses diversos), reconociendo que el estado se mantiene «no a pesar, sino precisamente en virtud de los conflictos sociales: de ellos se "nutre», al regularlos y controlarlos» ${ }^{25}$, lo que no parece poca cosa respecto a sus colegas de época.

22 Como afirma Domènech sobre el ambiente europeo de la revolución francesa y posrevolucionario, en un ensayo llamado a convertirse en un clásico del pensamiento político español: «Aquella burguesía, la de 1789, estaba más dispuesta [..] a «fraternizar» con el pueblo bajo que la nueva burguesía industrial de mediados del siglo XIX. Todavía en 1830, no se apreciaban en el dêmos fracturas patentes, manifiestamente irreparables, y la nueva sociedad civil posrevolucionaria, con todo y a pesar de todo, se ofrecía aún a la vista de algunos en la Europa continental como hogar de posible confraternización democrática, como un espacio en el que podían allanarse, si no todas, muchas barreras de clase [los subrayados son míos]; 1848 puso fin a esas ilusiones republicanas en Europa» (DOMĖNECH, A., El eclipse de la fraternidad: una revisión republicana de la tradición socialista, Ed. Akal, Madrid, 2019, p. 126). Será en este tan concreto ambiente, el de 1821, en el que Hegel escribirá sus Principios. Y, por el contrario, será en el posterior a la caída de 1848 en el que Marx hará lo propio, desarrollando la gran parte sustancial de su teoría crítica y proyecto revolucionario, que, no obstante, no tendrá -queda para otra ocasión discutir si por desgracia o por fortuna- la sistematicidad de la de Hegel. Quizás este apunte histórico pueda ser útil a la hora de trazar ciertas analogías y comparaciones entre ambos.

23 Y es que, como señala Marcuse: «En su raíz, la Filosofía del Derecho tiene un enfoque materialista. Hegel expone párrafo tras párrafo la infraestructura económica y social de sus conceptos filosóficos. Es verdad que deriva todas las realidades económicas y sociales de la idea, pero la idea está concebida en función de estas realidades y está en todo momento signada por ellas» (MARCUSE, H., Razón y revolución: Hegel y el surgimiento de la teoría social, Ediciones Altaya, Barcelona, 1994, p. 183).

24 SCHMITT, C., Hegel y Marx (Conferencia radical, 1931), disponible en: https://nochedelmundo.wordpress.com/2017/02/27/hegel-y-marx-por-carl-schmitt/amp/

25 DUQUE, F., Historia de la Filosofía moderna, op. cit., p. 485. 
Clarificada esta cuestión, puede comprenderse mejor el hecho de que, para Hegel, sea entonces sólo a través de la inserción de los individuos en estas clases como pueda conquistarse la efectiva realidad y objetividad ética, de tal forma que sólo así alcance el hombre su sustancialidad, dado que, para él, al fin y al cabo, «un hombre sin clase es una mera persona privada y no está en una universalidad real» $(\$ 207, \text { Obs. y Agr. })^{26}$. De esta manera, tal desarrollo lleva entonces necesariamente a afirmar que dicho sistema, dicha sociedad civil dividida en clases, contiene ya en y por sí la universalidad de la libertad (aunque sólo sea de manera abstracta) como derecho de propiedad, que alcanza realidad efectiva con su protección por parte de la administración de justicia $(\$ 208)^{27}$, segundo momento de la sociedad civil. Y es que «es a causa del sistema de la particularidad que el derecho deviene exteriormente necesario como protección de la particularidad» $(\$ 209, \text { Agr. })^{28}$. Este derecho alcanza su existencia objetiva y determinación verdadera en la ley, que tiene que plasmarse sistemática y positivamente y acompañarse de ciertas formalidades e instrumentos como los contratos que hacen pasar «la existencia inmediata y abstracta de mi derecho individual» (pensando ante todo en el de propiedad) en una «existencia en el saber y en la voluntad universales y existentes» $(\$ 217)^{29}$.

En este sentido, con la administración de la justicia, la idea, perdida en la particularidad de la sociedad civil, retorna así a su concepto: «a la unidad de la universalidad existente en sí con la particularidad subjetiva» (\$229). Pero dicha realización de la unidad necesita, para realizarse, el de la policía y la corporación, las cuales conforman el tercer y último momento de la sociedad civil ${ }^{30}$. Estas vendrían a atender el bienestar de los individuos, su particularidad, dado que pese a que la justicia (que anula la lesión de la propiedad y la personalidad, es decir, que asegura la persona y la propiedad libre) es muy importante para la sociedad civil, para Hegel será también esencial que «se asegure la subsistencia y el bienestar del individuo, esto es, que el bienestar particular sea tratado como derecho y realizado» $(\$ 230)^{31}$. $\mathrm{Y}$ tal inquietud le lleva precisamente a abordar la cuestión de cómo pueden

26 HEGEL, G. W. F., Principios de la Filosofía del Derecho..., op. cit., p. 280.

27 Ibid., p. 281.

28 Ídem.

29 Ibid., p. 290.

30 Ibid., p. 301. Y es que como afirma Eduardo Álvarez respecto a lo esencial de este punto en su filosofía política: «Hegel nos dice que es de la mayor importancia no confundir la verdadera universalidad con la mera comunidad: el concepto entendido como mera reunión de notas comunes que hace abstracción de lo particular sí justifica que se lo considere frío y muerto; pero, como totalidad concreta, el concepto pretende ser el poder de lo universal que se particulariza a sí mismo. Con la ayuda de esta categoría hay que concebir la vida (contra el vitalismo irracionalista), pero no sólo la vida orgánica, sino también la vida espiritual, como por ejemplo la que se manifiesta en la sociedad y en el Estado» (ÁLVAREZ, E., El saber del hombre: Una introducción al pensamiento de Hegel, Ed. Trotta, Madrid, 2001, p.111).

31 HEGEL, G. W. F., Principios de la Filosofía del Derecho, op. cit., p. 302. 
conciliarse los «diversos intereses» de las distintas clases que, como ya dijimos: «pueden entrar en conflicto entre sí», es decir, le lleva a tratar la lucha de clases.

Analizando lo que en su época comenzará a llamarse ya «el problema social», que con el desarrollo del capitalismo a lo largo del siglo XIX se convertirá sin duda en «el problema», sostendrá Hegel que, a través del estado, será necesaria establecer una regulación consciente que permita conciliar estos intereses diversos en posible pugna, cuyo fundamento último se encuentra en que «frente a la libertad de la industria y el comercio en la sociedad civil, el otro extremo está dado por la provisión y reglamentación del trabajo de todos por medio de instituciones públicas» $(\$ 236 \text { y Obs. })^{32}$. Como puede apreciarse sin demasiada complejidad, en este punto está Hegel anticipando de forma magistral el famoso conflicto trabajo-capital que luego Marx convertirá en punto central de su teoría social. Su objetivo, sin embargo, no es -y ya hemos señalado por qué creemos que no podría serlo- el de superar dicho conflicto, sino el de neutralizarlo, es decir, el de hacerlo lo más llevadero posible para todos los integrantes de la sociedad civil, dado que pese a que el individuo «tiene derecho a ganarse el pan de esta u otra manera [..] por otra parte, el público también tiene el derecho de reclamar que lo necesario sea producido del modo conveniente. Se deben satisfacer ambos aspectos, y la libertad de comercio no debe llevar a poner en peligro el bien general» $(\$ 236, \text { Agr. })^{33}$.

32 Ibid., p. 304. Sociedad civil a la que, por cierto, no dudará Hegel en Ilamar familia universal (\$239, p. 306). Porque, cabe recordarlo, Hegel está educado en la tradición revolucionaria democrática-fraternal iniciada en la Revolución Francesa. Y, como recuerda Michelet, el gran historiador de esta, en este sentido «aquella burguesía, imbuida de Voltaire y de Rousseau, era más amiga de la humanidad, más desinteresada y generosa que la que ha hecho el industrialismo» (MICHELET, J., Histoire de la Révolution Française [vol. I], Robert Laffont, París, 1979, p. 346). Ello puede darnos otra pista más de por qué Hegel puede todavía pensar que el problema de una sociedad compuesta por clases con intereses en conflicto puede solventarse sin tener que superarse: en el ambiente revolucionario-fraternal de la época era este un lugar común. Será sólo después, con el traslado del cariz revolucionario del movimiento democrático al movimiento comunista, cuando tal lugar saltará por los aires. Así, como dirá Marx en 1850: «la palabra que correspondía a esta imaginaria abolición de las relaciones de clase era la fraternité, la confraternización y la fraternidad universales. Esta idílica abstracción de los antagonismos de clase, esta conciliación sentimental de los intereses de clase contradictorios, esto de elevarse en alas de la fantasía por encima de la lucha de clases, esta fraternité fue, de hecho, la consigna de la revolución de Febrero» (MARX, K., Las luchas de clases en Francia de 1848 a 1850, Fundación Federico Engels, Madrid, 2015, p. 56). En esa concreta fraternité parecía confiar y moverse aún Hegel.

33 HEGEL, G. W. F., Principios de la Filosofía del Derecho..., op. cit., p. 305. Resulta curioso comprobar, y tiene todo el sentido lógico a la luz de su sistema, cómo por todo lo dicho no podrá Hegel sino postular la economía política como la ciencia que tiene su comienzo en el intento de entendimiento, esto es, en la «esfera del factor de conciliación» (\$189, p. 267). Esta conciliación sólo es posible debido a que ambos polos se entienden «enfrentados» en el sentido de representar intereses distintos. El descubrimiento de que tales intereses, tales polos, no son sólo diversos, sino que son antagónicos e irreconciliables, es decir, que no se pueden satisfacer a la vez, representa entonces precisamente el paso de la economía política (como ciencia del entendimiento entre clases) a la crítica de la economía política (como ciencia de la revolución y la superación de la escisión en clases). 
Aquí se observa el modo como Hegel llega a una de las partes más brillantes de su exposición, en la que pese a no poder apreciarla aun completamente (insistimos, en cuyo caso no tendría otra opción lógica que tratar de superarla) parece entrever la contradicción básica que atravesará a todas las sociedades burguesas basadas en el modo de producción capitalista. Si bien, por un lado, «con la universalización de la conexión entre los hombres, a causa de sus necesidades y del modo en que se preparan y producen los medios para satisfacerla, acrecienta la acumulación de riquezas», por otro lado «se acrecienta también la singularización y limitación del trabajo particular, y con ello la dependencia y miseria de la clase ligada a ese trabajo» $(\$ 243)^{34}$. Y debido a este conflicto, pues, anticipa Hegel el surgimiento de una plebe, propensa como ningún otro grupo a una «íntima indignación contra los ricos, la sociedad, el gobierno» que, para más inri, «toma aversión al trabajo» $(\$ 244, \text { Agr. })^{35}$.

El intento de evitar el surgimiento de esta plebe, por una cuestión ética, pero sobre todo por la potencialidad revolucionaria que ésta parece contener en su seno (la cual podría poner en peligro toda la organización política estatal), será por tanto el objetivo de todo estado, que deberá por ello estar pendiente de la cuestión social, esto es, de tratar de garantizar el bienestar de todos sus miembros. Objetivo, no obstante, ciertamente complejo, dado que Hegel parece ya reconocer el surgimiento de esa intrínseca contradicción que atravesará la sociedad civil (burguesa), por la que, pese a toda la inmensa riqueza producida por ella, «no es suficientemente rica, es decir, no posee bienes propios suficientes para impedir el exceso de pobreza y la formación de la plebe» $(\S 245)^{36}$. No es complicado imaginarse a cierto revolucionario renano vislumbrando en estos parágrafos al incipiente proletariado industrial de la época. Así, como afirma Frank Ruda, Hegel parece percibir ya esta cuestión como un problema de gran relevancia social, el cual, sin embargo, es incapaz de asumir y tratar de solventar (ya que, como sabemos, tras estas breves pinceladas abandonará en sus Principios esta cuestión). Por ello, será precisamente la cuestión de la plebe, como problema respecto al cual la filosofía política hegeliana falla, la que constituirá el punto de partida de la transición de Marx respecto a Hegel, transición materializada precisamente en el paso del concepto de «plebe» al de «proletariado» ${ }^{37}$.

37 RUDA, F., Hegel's Rabble: An investigation into Hegel's Philosophy of Right, Continuum Studies in Philosophy, London, 2011, pp. 24 y 25. Hemos podido discutir este extremo con Félix Duque, para el cual, en una visión sumamente interesante y que creemos oportuna incorporar, esta lectura de Ruda no es convincente, pues la plebe, en todo caso, correspondería al lumpenproletariado marxiano, clase sin clase para el Marx del Manifiesto, mientras que el proletariado, en tanto que postulado por éste como clase universal, podría equivaler en todo caso al funcionariado 
Con todo lo dicho parece evidente por qué el paso adelante de Marx respecto a Hegel tiene entonces que realizarse necesariamente de forma total, llevándose hasta sus últimas consecuencias. Pues una vez que el renano niega que la división (para él escisión) de la sociedad en clases sea natural, sino que, muy al contrario, se trata de un vicio de largo alcance capaz de corregirse, la inversión del esquema hegeliano de la sociedad civil (y, por ende, del estado) no puede sino ser completa: en dicho caso la sustancialidad del hombre y la universalidad de la libertad sólo pueden llegar precisamente con la superación de la sociedad de clases escindida, que tiene además como presupuesto tanto la abolición de la propiedad privada de los medios de producción como la superación del estado (el salto hacia adelante del sistema del que hablamos antes), lógicamente incapaz de conciliar o cohesionar intereses de clases que se ven -ya sí- como antagónicos y, por tanto, responsables de producir ese «exceso» inasumible que constituye la plebe, el proletariado, que será precisamente para Marx la piedra de toque para superar la escisión ${ }^{38}$.

Pues bien, tras estas observaciones y llegando ya al final de este apartado, es recalcable que para Hegel esta previsión del poder de policía, esta acción consciente y reguladora del estado a través de diversas políticas públicas destinadas a garantizar el bienestar de los miembros de la sociedad civil, «realiza y conserva lo universal que está contenido en la particularidad» $(\$ 249)^{39}$. Ahora bien, como de acuerdo con la idea la particularidad toma a este universal como fin, «lo ético vuelve como algo inmanente a la sociedad civil. Esta es la función de la corporación» $(\$ 249)^{40}$. La corporación, encargada así de contribuir al bienestar de sus miembros, se convierte entonces en una segunda familia, en la «segunda

en Hegel, al que otorgaría ese mismo carácter universal. En nuestro caso, no obstante, seguimos viendo sumamente interesante la tesis de Ruda, no sólo por su potencial analítico, sino sobre todo por el potencial político-revolucionario de dicha tesis.

38 Pero, como tan acertadamente señala Schmitt en un pequeño texto tan sorprendente como acertado, dicha piedra de toque, dicha particularidad, no podría haber emergido sino tras Hegel, pues sólo «con el poder de una lógica específicamente hegeliana», de una filosofía para la cual «todo conocimiento histórico verdadero es conocimiento del presente», necesariamente centrada por ello en la realidad política concreta actual, tuvo Marx «que aventurarse en la economía y captar lo económico, porque en el proceso dialéctico del devenir político concreto, el Estado -que todavía parecía tener el monopolio de lo político-, era víctima del engaño de la idea, pues las sustancias activas de lo político estaban ahora situadas en una sociedad industrial aparentemente apolítica y económicamente determinada». Así, la evidencia marxista del proletariado como «única clase remanente en la sociedad industrial que puede convertirse en el portador activo de un desarrollo histórico posterior y lograr la nueva condición de una humanidad sin clases, [..] la garantía inherente característica de la corrección de esta afirmación marxista, es, en su estructura, completamente hegeliana, y sólo puede ser entendida en términos hegelianos. Sin la dialéctica de una construcción hegeliana de la historia, no sería evidente por qué, después de toda experiencia histórica previa, esta nueva clase no podría dejarse atrapar por el inmenso poder y riqueza del mundo capitalista» (SCHMITT, C., Hegel y Marx..., op. cit.).

39 HEGEL, G. W. F., Principios de la Filosofía del Derecho..., op. cit., p. 312.

40 Ídem. 
raíz ética del estado, hundida en la sociedad civil», de tal forma que reúne todos los momentos escindidos en la sociedad civil «en la particularidad reflejada sobre sí de las necesidades y goces y en la universalidad jurídica abstracta; con esta unión el bienestar particular se realiza como derecho» (\$252 y 255) ${ }^{41}$.

La sociedad civil termina entonces por presentarse en Hegel como momento intermedio entre la familia y el estado, al cual se pasa a través de la corporación, la que a su vez retoma la universalidad, pero cuya finalidad limitada y finita tiene sin embargo «su verdad [..] en la finalidad universal en y por sí y en su absoluta realidad», por lo que «la esfera de la sociedad civil pasa así al estado» $(\$ 256)^{42}$, momento culmen del desarrollo de la eticidad. Así, es precisamente en la búsqueda del aseguramiento de sus necesidades, verdadero fin de la sociedad civil, cuando esta se otorgará una constitución jurídica capaz de servir como medio para la seguridad de las personas y la propiedad y se dotará de un orden y una estructura exterior que consiga conciliar los intereses particulares y los comunes. Y la combinación de ambos elementos será precisamente lo que conformará el estado. Ahora bien, cabe señalar para terminar que, pese a que la sociedad civil parece presentarse como un momento anterior al estado, Hegel, no obstante, afirmará que la formación de la sociedad civil es posterior a la de éste, al cual presupone y «necesita tener ante sí como algo independiente para existir» $(\$ 182, \text { Agr. })^{43}$. En este sentido, es interesante comprobar cómo Hegel, para cerrar su apartado, no postula un tránsito de la sociedad civil al estado a la manera en la que lo hizo en el tránsito de la familia a la sociedad civil, como una especie de disolución de la primera en la segunda, sino que precisamente acaba afirmando que «el estado es lo primero, dentro del cual la familia se desarrolla en sociedad civil, y es la idea misma del estado la que se separa en estos dos momentos» $(\S 256, \text { Obs. })^{44}$.

41 Ibid., p. 314-316. Nótese que, tras la defensa de Hegel en el apartado de la administración de justicia de la sistematicidad y positividad de las leyes, anticipadora de los grandes principios de los actuales estados de derecho, está ahora Hegel postulando en esta parte de su obra muchos de los fundamentos en los que se basará la consolidación de los modernos estados de bienestar, vislumbrando el conflicto social, el conflicto trabajo-capital, al que estos tendrán que hacer frente y por el cual surgirán. Nada mal para una obra en la que se supone que solo estamos ante un mero apologeta del reaccionario estado prusiano...

42 Ibid., op. cit., p. 316.

43 Ibid., op. cit., p. 260.

44 Ibid., op. cit., p. 317. Al respecto de este punto son más que interesantes muchas de las apreciaciones del joven Marx de la Crítica de la Filosofía del Derecho de Hegel. Así, si bien parte este de una premisa errónea, pues afirma: «Que el Estado es, con respecto a la familia y a la sociedad civil, una «necesidad externa» iba ya implícito, en parte, en la categoría de la «transición» y, en parte, en su relación consciente» (lo que sabemos ya que es falso, pues Hegel no postula este avance en términos de transición), creemos que acierta, sin embargo, al señalar «la antinomia no resuelta» que plantea Hegel al presentar el estado a la vez como necesidad externa y como fin inmanente, postulando familia y sociedad civil en un caso en una relación de dependencia y subordinación y en otra de armoniosa identidad interna (MARX, K., Escritos de juventud, Fondo de Cultura Económica, México D.F., 1982, p. 319-324). Pero se trata, además, de 


\section{El estado hegeliano: el «reconocimiento universal de las partes en la totalidad social» en disputa}

Con una sustancia ética que ha conquistado su forma infinita a través del desarrollo de la sociedad civil, llegamos a un momento del sistema hegeliano en el que «el espíritu es objetivo y real como totalidad orgánica» $(\$ 256, \text { Obs. })^{45}$. Esta totalidad orgánica no es otra que el estado, que constituye así para Hegel la «realidad efectiva de la idea ética», «realidad de la voluntad sustancial», «lo racional en y por sí», «totalidad ética» donde se produce «la realización de la libertad» $(\S 257,258 \text { y Obs. })^{46}$. Dicha conversión en realidad efectiva se producirá porque, para Hegel, es en la eticidad, cuyo momento culmen es el estado, donde la libertad pasaría de su mero «estar ahí» del derecho a formar una verdadera «segunda naturaleza», superior incluso a la primera, la naturaleza física ${ }^{47}$.

En este sentido, toda la primera parte de la exposición hegeliana del estado se presenta como un elaboradísimo estudio del juego y tensión entre particularidad y universalidad, entre intereses particulares e interés general, entre voluntad individual y voluntad común. Y es que Hegel, espectador preferente de ese momento histórico en el que parece que comienza a consolidarse el modo de producción capitalista y, consiguientemente, la sociedad burguesa, parece intuir ya que este será el problema que acabará desgarrando dicho mundo. Esta aproximación se lleva a cabo, sin embargo, con una premisa bien clara: el estado, como unidad sustancial portadora en su seno de los intereses del todo, «tiene un derecho superior al individuo, cuyo supremo deber es ser miembro

una cuestión de suma relevancia porque, como afirma Abensour, es precisamente desde aquí desde donde Marx «invocando las circunstancias -arbitrarias- en que se efectúan las mediaciones, practica la inversión: el Estado no es el sujeto que se pone a sí mismo y se fenomenaliza en la sociedad civil y en la familia», de tal forma que "sustituyendo el esquema invertido y mistificador de Hegel [..] por las relaciones reales, Marx escribe las fórmulas bien conocidas que sitúan al Estado en la dependencia de las esferas de donde emerge» (ABENSOUR, M., La democracia contra el Estado, Ediciones Colihue, Buenos Aires, 1998, p. 60). En todo caso, se trata de un punto de gran complejidad, pues lo que Hegel parece estar haciendo en sus Principios es describir el modo en el que la conciencia filosófica va alcanzando en su desarrollo dialéctico especulativo las distintas partes que conforman el espíritu objetivo, de tal forma que la presentación de dichas partes al modo de un desarrollo temporal o sucesión cronológica no sería del todo correcta (por mucho que, como hemos visto, el propio Hegel afirme explícitamente que «el estado es lo primero, dentro del cual la familia se desarrolla en sociedad civil» [\$256, Obs.]).

45 HEGEL, G. W. F., Principios de la Filosofía del Derecho, op. cit., p. 317.

46 Ibid., p. 318 y 319. Pese a las grandilocuentes palabras con las que Hegel presenta al estado, hay que señalar que, frente a la sociedad civil como momento abstracto de la realidad de la idea, apariencia exterior que solo es «totalidad relativa y necesidad interior», el avance lógico hegeliano hacia el estado sólo puede presentar a este ya así (por cierto, categoría esta de «totalidad» que, como supieron ver algunas de las mejores mentes de la tradición marxista, que curiosamente también fueron grandes hegelianos, constituye una categoría esencial para toda teoría que quiera tener una verdadera perspectiva revolucionaria).

47 DUQUE, F., Historia de la Filosofía Moderna, op. cit., p. 811. 
del estado» $(\$ 258)^{48}$. Ahora bien, como lo racional en síy por sí, y dado que la racionalidad consiste en «la unidad y compenetración de la universalidad y la individualidad» $(\$ 258, \text { Obs. })^{49}$, el estado debe asegurar también esa libertad individual y voluntad particular de cada individuo.

De esta manera, Hegel comienza su exposición abordando primero la idea del estado, respecto a la que tiene palabras tan grandilocuentes como las que hemos señalado hace un momento, para pasar luego a analizar su realidad inmediata, es decir, el estado como organismo político, como estructura históricamente determinada. Así, como explícitamente afirmará: «Para concebir la idea del estado no es necesario observar estados e instituciones determinados, sino considerar la idea misma, ese Dios real» $(\S 258, \text { Agr. })^{50}$. Pese a lo extraño que esto pueda parecer, sólo a partir de esta premisa puede comprenderse que sus grandes palabras para con el estado no son en absoluto ningún tipo de apología a ningún tipo de estado - como el prusiano-- Porque Hegel no estudia ningún estado concreto ni quiere postular un modelo de estado ideal que sirva «como modelo de construcción y a la vez criterio externo para medir el valor y sentido de los Estados realmente existentes» ${ }^{51}$. Muy al contrario, Hegel quiere comprender cuáles son las condiciones de posibilidad e inteligibilidad de cualquier estado en cuanto tal, dado que su interés no está en lo existente, sino en su actualidad ${ }^{52}$. Así, igual que para Hegel el pan sólo es pan cuando es comido por el hombre, el estado solo es estado si cumple dichas condiciones de posibilidad, que básicamente exigirían su capacidad de expresar la libertad y el reconocimiento universal de las partes en la totalidad social, es decir, de conciliar lo particular y lo universal ${ }^{53}$.

48 HEGEL, G. W. F., Principios de la Filosofía del Derecho, op. cit., p. 318.

49 Ibid., p. 319.

50 Ibid., p. 324.

51 DUQUE, F., Historia de la Filosofía Moderna, op. cit., p. 820.

52 Véase PIPPIN, B. R., Hegel's realm of shadows, 2018, The University of Chicago Press, Chicago, p. 54-55 y 62. Agradezco a mi compañero Alejandro Fernández su insistencia en esta cuestión durante nuestra aproximación al tema.

53 Aproximación hegeliana a la realidad que resulta ciertamente problemática por lo que de teleología parece incorporar, lo cual parece hacerla pasar por alto que los propios fines a los que un objeto o estructura estarían llamados a satisfacer vendrían determinados ya por nuestra propia conciencia (colectiva e histórica), determinada a su vez por la totalidad social en la que vivimos y pensamos, la cual, como señalará Marx, está totalmente influida por la propia lucha de clases, en tanto que pugna por consolidar formas de entender la realidad que sean útiles para satisfacer los intereses de una clase u otra. Así, coincidiendo aquí sí con el joven Marx de la Crítica de la Filosofía del Derecho de Hegel: «Se parte de la idea abstracta, cuyo desarrollo en el Estado es la constitución política. No se trata, por tanto, de la idea política, sino de la idea abstracta en el elemento político. Al decir que «este organismo (es decir, el Estado, la constitución política) es el desarrollo de la idea en sus diferencias», etc., aún no sé nada de la idea específica de la constitución política» (MARX, K., Escritos de juventud, op. cit., p. 326). Y, con ello, acusará Marx a Hegel de olvidar la política, ya que el movimiento del pensamiento hegeliano correspondería a un esquema lógico (el de las relaciones de la Idea y de sus momentos) alejado de 
De esta forma, pasando ya a la esfera de la realidad inmediata del estado, inseparable de su idea, dado que «el Estado ha de corresponder a la Idea lógica [porque] no es pues ni un Estado concreto, existente, ni un Estado ideal, sino... la Idea del Estado» ${ }^{54}$, la sustancia del estado se hunde hacia dentro como constitución y derecho político interno y hacia fuera como derecho internacional $(\$ 259)^{55}$. Así, en referencia al ámbito interno, la esencia del estado moderno no puede ser entonces otra que la de tratar de lograr la conciliación y vinculación entre los intereses particulares, «la plena libertad de la particularidad», y lo universal. Esta vinculación será precisamente lo que Hegel denominará $l i$ bertad concreta, aquella que el estado viene a convertir en realidad efectiva ( $\$ 260$ y Agr. $)^{56}$. Y con ello, el estado, como momento más elevado del espíritu objetivo, constituiría y vendría a realizar la absoluta compenetración de todos los intereses y fines particulares del espíritu subjetivo (mirando, por así decir, enciclopédicamente «hacia abajo») y de la universalidad de la voluntad, orientada a la absoluta transparencia del espíritu consigo (si miramos «hacia arriba») ${ }^{57}$.

toda inserción en el elemento político y de toda confrontación con sus determinaciones, por lo que Hegel estaría olvidando la esencia de lo político y de cada poder en particular, determinados por la naturaleza del concepto y no por su naturaleza propia, no pensando así el estado sino a partir de determinaciones lógico-metafísicas (ABENSOUR, M., La democracia contra el Estado, op. cit., p. 66). «De este modo», sentencia Marx, «la crítica verdaderamente filosófica de la constitución actual del Estado no se limita a poner de manifiesto la existencia de contradicciones, sino que las explica, trata de comprender su génesis y su necesidad, las toma en su propia significación. Ahora bien, esta comprensión no consiste, como piensa Hegel, en reconocer por todas partes las determinaciones del concepto lógico, sino en comprender la lógica específica del concepto específico» (MARX, K., Escritos de juventud, op. cit., p. 403). No obstante, señala Ruiz Sanjuán que, en este punto, mientras que la crítica feuerbachiana se limita básicamente a objetar a Hegel que ignora la realidad sensible, Marx parece comprender que este modo de plantear la cuestión no alcanza a la filosofía hegeliana, la cual no prescinde de lo sensible, sino que lo comprende dialécticamente, poniendo la esencia de la realidad sensible no en ella misma, sino en su otro, en el pensamiento. De esta forma la crítica de Marx iría dirigida a dicha inversión en la expresión de la realidad, por la cual queda suprimida la verdad de lo sensible, de lo material, que es transferida a su opuesto, al concepto, su verdadero fundamento. Así, a diferencia de Feuerbach, la crítica de Marx a Hegel versaría sobre lo insuficiente y erróneo del papel de la mediación en el último, no en la ausencia de una verdadera inmediatez en este (RUIZ SANJUÁN, C., Historia y sistema en Marx, Siglo XXI, Madrid, 2019, p. 36). Y es que como afirma Lukács, y para terminar ya con esta cuestión que tanto interés me ha despertado en el estudio de Hegel: «La incapacidad de penetrar en el objeto mismo cobra entonces, como expresión intelectual, la idea de unas fuerzas motoras trascendentes que construyen y configuran de una manera mitológica la realidad, la relación entre los objetos, nuestras relaciones con ellos, su transformación en el proceso histórico. Al descubrir Marx y Engels "la producción y la reproducción de la vida como el momento en última instancia determinante de la historia", han conseguido finalmente la posibilidad y la perspectiva adecuada para romper con toda mitología» (LUKÁCS, G., Historia y consciencia de clase, op. cit., p. 78).

54 DUQUE, F., Historia de la Filosofía Moderna, op. cit., p. 831.

55 HEGEL, G. W. F., Principios de la Filosofía del Derecho, op. cit., p. 324.

56 Ibid., p. 325 y 326.

57 DUQUE, F., Historia de la Filosofía Moderna, op. cit., p. 833. 
Ahora bien, cabe aclarar que Hegel afirma que dicha vinculación entre lo universal y la plena libertad de la particularidad «es» o «está» en la esencia del estado moderno $(\$ 260 \text {, Agr. })^{58}$, de tal forma que el estado parece no postularse como el encargado de crear la situación en la que dicha vinculación se produzca - pudiendo existir otra situación alternativa en la que tal vinculación pudiera no hacerlo- ${ }^{-}$, sino que más bien parece mostrar que lo universal y lo particular están ya necesariamente vinculados en sí y por sí. En este sentido, el estado queda planteado como una necesidad exterior $(\$ 261)^{59}$, porque el bienestar de los individuos y el cumplimiento de sus intereses individuales, la plena libertad de la particularidad solo puede darse en su seno. Y, precisamente al darse, produciría esa cohesión y convivencia general, es decir, las bases de dicho estado, con lo que ambos polos se determinarían y contendrían así mutuamente, con la consecuencia lógica de que el hombre, como máximo exponente de lo particular, solo existiría en el estado, en cuanto representante de lo universal.

Pues bien, una vez aclarado que esta vinculación entre lo universal y lo particular no es, por tanto, una creación artificial que le corresponda concebir al estado, sino que puede entenderse como su propio presupuesto, su propia esencia $^{60}$, debe señalarse, no obstante, que, pese a no ser una creación artificial, sí que necesitaría asegurarse. Y en este momento, como afirma Félix Duque: «El sólido «vínculo» aquí reclamado puede decirse con una palabra: institucionalización» ${ }^{61}$. Será entonces la institucionalización, elemento fundamental de los grandes estados de derecho, la encargada de garantizar y materializar en derechos concretos estas voluntades particulares, los intereses privados de los ciudadanos que transparecen en la voluntad absoluta que el estado exterioriza, de tal forma que ambos polos sólo pueden darse el uno con el otro al mismo tiempo: «Estas instituciones constituyen la Constitución, es decir, en lo particular, la racionalidad desarrollada y realizada» $(\$ 265)^{62}$. Y, con todo ello,

58 HEGEL, G. W. F., Principios de la Filosofía del Derecho, op. cit., p. 326.

59 Ídem.

60 Y es sorprendente comprobar que Hegel, con la genial sistematicidad que le distingue, consigue vincular lo particular a lo universal incidiendo a la vez en las dos esferas que configurarían dicha particularidad: tanto el polo subjetivo, «la plena libertad», como el polo objetivo, «el bienestar», de tal forma que ambos quedan indisolublemente unidos a su realización en el estado, lo que refuerza su posición de necesidad exterior, en orden de que no se produzca ninguna grieta en la que dicha vinculación pueda quebrarse.

61 DUQUE, F., Historia de la Filosofía Moderna, op. cit., p. 826.

62 HEGEL, G. W. F., Principios de la Filosofía del Derecho, op. cit., p. 331. Como puede observarse, la idea del estado no puede entonces separarse de su realidad inmediata, como han pretendido algunos autores como Pelczynski, que, para tratar de superar esta tensión, han querido establecer una especie de dualidad en torno a la categoría del estado en Hegel, que separaría el estado, así sin más, como representante de la idea de estado, del estado político, como representante de las estructuras políticas determinadas que Hegel analiza bajo el subtítulo de «derecho político interno» (en: Estudios sobre la «filosofía del Derecho» de Hegel, Centro de Estudios Constitucionales, Madrid, 1989, pp. 262-266). A mi juicio, tal metodología de aproximación al estado 
inserto en la tradición liberal, pero alejándose del liberalismo atomista e individualista predominante, Hegel parece postular una especie de liberalismo orgánico esencial para garantizar su anhelado orden ${ }^{63}$.

Entonces, además de todo lo dicho en referencia a la realidad inmediata del ámbito interno del estado, y en parte debido a ello, Hegel se ve obligado a situar a la cabeza de dicho estado a alguien que posea «su individualidad en virtud de su existencia natural y no en virtud de su existencia social, que sea lo que es por naturaleza y no por los mecanismos sociales» ${ }^{64}$. Ese alguien es el monarca, el cual reúne «los diferentes poderes [legislativo y ejecutivo, que han de estar separados] en una unidad individual, que es por lo tanto la culminación y el comienzo del todo» $(\$ 273)^{65}$. La monarquía constitucional, al estilo del Reino Unido, verdadero modelo en el que Hegel parece tener sus ojos puestos, se presenta, así, como «la obra del mundo moderno, en el cual la idea sustancial ha alcanzado su forma infinita» y, por tanto, el objeto de la historia universal general $(\$ 273, \text { Obs. })^{66}$. De este «poder del príncipe» deriva entonces la reflexión sobre la soberanía, en la cual converge todo el sistema político hegeliano, afirmándose primero hacia dentro -soberanía interior del estado respecto a la sociedad civil y el pueblo-, para hacerlo después hacia afuerasoberanía exterior del estado y derecho a la guerra- $(\$ 281,321 \text { y } 334)^{67}$. Como indica Félix Duque, es precisamente respecto a la soberanía y el derecho político exterior cuando llegamos al «momento de máximo poderío y autosuficiencia por parte del Estado, ese «Leviatán» ahora astutamente virado por Hegel hacia el exterior y que no reconoce poder superior alguno sobre la tierra ${ }^{68}$.

Esta postulación absoluta del estado como ente supremo que no puede estar sujeto a norma más alta, este sobredimensionar su tarea histórica, lleva entonces a la apariencia de que «los Estados soberanos quedan fuera del mundo de la interdependencia civil; existen en un «estado natural»» ${ }^{69}$. No obstante, como

hegeliano, pese a las facilidades explicativas que trae consigo, desvirtúa por completo esta parte de su sistema, dado que no se trata dos momentos separables de este, cuyo análisis, por tanto, pueda diferenciarse, sino que esta realidad inmediata forma parte de la propia idea y esencia del estado, cuyas estructuras, devenidas históricamente, son examinadas a la luz de su curso lógico.

63 DUQUE, F., Historia de la Filosofía Moderna, op. cit., p. 827.

64 MARCUSE, H., Razón y revolución..., op. cit., p. 213.

65 HEGEL, G. W. F., Principios de la Filosofía del Derecho, op. cit., p. 353. Para la profundización en esta cuestión véase el texto de Bernard Bourgeois «El príncipe hegeliano», en: Estudios sobre la «filosofía del Derecho» de Hegel, op. cit., pp. 289-318.

$66 \mathrm{Ibid} .$, p. 354. Para profundizar en aquello que más parece interesar a Hegel de la forma política británica (y también de la francesa y alemana) léase su $\$ 544$ de la Enciclopedia.

67 Ibid., p. 369, 406 y 417.

68 DUQUE, F., Historia de la Filosofía Moderna, op. cit., p. 840.

69 MARCUSE, H., Razón y revolución..., op. cit., p. 218. Naturalización del estado que tiene implicaciones políticas de primer orden, como rápidamente serán conscientes y señalarán los comunistas, sobre todo tras su divorcio en 1848 del movimiento democrático, de fuerte carácter estatalista. 
sabemos, en Hegel el estado ha de responder aún a una instancia superior que, de hecho, funciona como cierre de cláusula de esta parte de su sistema: se trata del «espiritu del mundo», absoluto e incondicional, último momento del espíritu objetivo que afirma que el estado posee su verdadero contenido en la historia universal, «despliegue y realización del espíritu universal» (\$340 y 342) ${ }^{70}$. Así, como explícitamente afirmará Hegel en uno de los primeros parágrafos sobre el estado:

Los estados [..] son independientes unos de otros, y su relación solo puede ser por lo tanto exterior, por lo que tiene que haber por encima de ellos un tercer elemento que los una. Este elemento es el espíritu, que se da realidad en la historia universal y se constituye en juez absoluto de aquellos [..] El único juez absoluto que siempre hace valer sus fueros contra lo particular, es el espíritu en y por sí, que se expone en la historia del mundo como lo universal $(\$ 259, \text { Agr. })^{71}$.

Aunque, de nuevo, y en la senda de esa magnificación y naturalización del estado, su gran filosofía del derecho termina tratando del mundo germánico -último de los cuatro mundos histórico-universales- con un parágrafo en el que afirma que: «ha devenido objetiva la verdadera reconciliación, que despliega al estado como imagen y efectiva realidad de la razón; allí la autoconciencia encuentra la realidad de su saber y querer sustancial en un desarrollo orgánico» $(\$ 360)^{72}$.

Pues bien, como hemos podido observar, toda la filosofía política esbozada por Hegel en sus Principios de la Filosofia del Derecho, especialmente a partir del abordaje de la sociedad civil y el estado, momentos en los que nosotros nos hemos centrado, constituyen un magnífico y complejísimo intento para tratar de lograr el reconocimiento universal de las partes en la totalidad social, condición de posibilidad para la libertad, es decir, de conciliar lo universal y lo particular en un mundo que empieza a dar muestras de que ese problema puede acabar por desgarrarlo. Hegel piensa que el estado es el organismo lógicamente llamado para llevar a cabo dicha tarea. Sin embargo, como hemos sostenido, creemos que dicha hipótesis parte del hecho de que Hegel está vislumbrando una sustancia (modo de producción capitalista) que aún no se ha desarrollado al completo, lo que no le permite ver su verdadera forma (sociedad escindida en clases con intereses antagónicos e irreconciliables).

Tal ausencia será entonces la que le permitirá entender que el estado puede llegar a ser capaz de cohesionar y conciliar dicha sociedad, lo que le convertiría, por tanto, en «realidad efectiva de la libertad concreta» $(\$ 260)^{73}$. Frente a

70 HEGEL, G. W. F., Principios de la Filosofía del Derecho, op. cit., p. 420.

71 Ibid., p. 325.

72 Ibid., p. 429.

73 Ibid., p. 325. 
ello, sin embargo, como ya sostuvimos respecto a la sociedad civil, Marx aparece como solución de continuidad lógica y necesaria respecto a Hegel, porque es él quien, tras el desarrollo completo de dicha sustancia, puede ser ya consciente de su verdadera forma, que muestra además al estado como lógica e intrínsecamente incapaz de lograr el reconocimiento universal de las partes en la totalidad, es decir, de «realizar la libertad» ${ }^{74}$. Así, una vez mostrado que ningún estado existente puede lograr tal objetivo (recordemos, condición de posibilidad para el propio Hegel para hablar de un verdadero estado) bajo las relaciones de producción capitalistas, responsables de ese «exceso» que Hegel llamará plebe y Marx proletariado, exceso insalvable, inasumible e irreconciliable, la superación del estado, piedra de toque del marxismo, aparece como respuesta lógica y necesaria en tanto que superación de esa sociedad escindida y superación de dicho exceso, logrando la verdadera reconciliación entre universalidad y particularidad pretendida por Hegel.

\section{Conclusiones}

Como hemos podido comprobar a lo largo del trabajo, la aproximación hegeliana al estudio de la sociedad civil y el estado incorpora elementos críticos sumamente relevantes para su época. Así, en la exposición lógica de esta parte de su sistema, muy alejados de cualquier tipo de apología o justificación de ningún estado existente (y mucho menos del reaccionario estado prusiano, lugar común de los críticos a Hegel, entre los que se encontrará el joven Marx),

74 Tesis compartida por autores como Abazari en Hegel's ontology of Power o Robert Pippin en Did Hegel comprehend its own time in thought? Y es que, como afirma Pérez Soto en un artículo tan polémico como brillante, Hegel muestra como ningún otro que «la sociedad humana está atravesada por una conflictividad esencial, que proviene del orden más íntimo de lo real, y en que la libertad debe ser considerada como un espacio pleno de deseo y contraposición, y a la vez inseparable de las situaciones históricas y sociales que la enmarcan, y en que puede desenvolverse», con lo que da a la violencia un papel esencial (porque «la contradicción, que la anima, está arraigada en el orden mismo del Ser») y objetivo (porque "su realidad excede largamente a las voluntades individuales, y sólo puede ser contenida en un espacio social, a través de mecanismos que exceden también a las buenas o malas voluntades individuales»). Así, al no poder esta suprimirse, será el intento de lograr la mediación de dicha violencia, de lograr una sociedad en que la libertad no se destruya a sí misma, lo que llevará a Hegel a pensar lógicamente en el estado de derecho como solución. Pero, precisamente, será a partir de estos mismos fundamentos desde los que postulará también Marx la necesidad de superarlo, tras «la constatación de que el Estado de Derecho, que debería ser el espacio para negociar y mediar las diferencias, en realidad favorece sistemáticamente a la burguesía». Así, si bien «la enorme, la abismal diferencia entre el cálculo de Marx y el de Hegel queda establecida, sobre esta base común, en torno a la posibilidad de mediar socialmente la violencia», no obstante «lo que para Hegel es la garantía posible de una paz capaz de mediar la violencia esencial, para Marx no es sino la institucionalización de esa misma violencia apareciendo falsamente como paz» (PÉREZ SOTO, C., Sobre la relación entre Hegel y Marx, Revista Herramienta, disponible en: Sobre la relación entre Hegel y Marx (herramienta.com.ar). 
pueden rastrearse elaboraciones cargadas de grandes potencialidades revolucionarias. Y es que Hegel postula que una verdadera sociedad, que es el sujeto libre de su propio progreso y reproducción, sólo puede ser concebida como una sociedad que materialice la libertad consciente. Será precisamente la ausencia real y concreta de dicha libertad dentro de la sociedad civil la que le habría negado a ésta el título de realización final de la razón, lo que le exigirá a Hegel el paso lógico al estado, que, por parecer ser ya capaz de conciliar particularidad y universalidad, es decir, de cohesionar los intereses individuales de los miembros de la sociedad civil y el interés general de la comunidad, es por ello «realidad efectiva de la libertad concreta» ${ }^{75}$.

Será, no obstante, precisamente bajo estas premisas hegelianas, las de configurar un sujeto libre que conscientemente materialice su propia libertad y la de fraguar una comunidad donde se haga efectivo el reconocimiento universal de las partes en la totalidad, bajo las cuales la filosofía de Marx tomará el relevo $^{76}$. En este sentido, Hegel señala el camino a través del estado para llevar a cabo tal tarea, pero dicho camino se demuestra lógicamente incorrecto (incapaz) para hacerlo, dado el desarrollo de la sustancia y la forma a la que ésta da lugar. Y, con todo ello, para Marx la conclusión lógica no podrá ser ya otra que:

La libertad en este terreno sólo puede consistir en que el hombre socializado, los productores asociados, regulen racionalmente ese metabolismo suyo bajo su control colectivo, en vez de ser dominados por él como un poder ciego [..] con el mínimo empleo de fuerzas y bajo las condiciones más dignas y adecuadas a su naturaleza humana ${ }^{77}$.

El punto crucial será entonces que tal tarea solo podrá realizarse en una comunidad universal de productores libres y asociados en la que «el libre desarrollo

75 Y en este sentido, como afirma Schmitt: «la línea de desarrollo histórico-filosófica que Hegel construyó es completamente revolucionaria incluso en el sentido marxista, ya que es una línea de progreso en la conciencia de la libertad. Así, en el contexto de los siglos XVIII y XIX, cada una de estas tres palabras - progreso, conciencia, libertad- es un concepto revolucionario», por lo que lo decisivo desde el punto de vista de la filosofía hegeliana «es la dialéctica concreta del actual desarrollo político efectivo, el funcionamiento de un espíritu que está siempre presente, nunca meramente en el pasado, o simplemente en el futuro» (SCHMITT, C., Hegel y Marx..., op. cit.).

76 Porque no es casualidad que sea precisamente tras el exhaustivo estudio por parte de Marx de la filosofía del derecho de Hegel cuando avance este progresivamente de «una posición básicamente ilustrada, a partir de la cual considera que la transformación de la conciencia de los hombres puede dar lugar a la transformación de las relaciones sociales existentes, hasta una posición comunista, en la que se abandona dicha pretensión y se establece la necesidad de revolucionar en la práctica las condiciones materiales de vida de la sociedad», dado que, a partir de Hegel, Marx toma conciencia ya de que dicha «esfera política está configurada a partir de la sociedad civil, y que es aquí donde hay que buscar las causas de la enajenación del hombre de su esencia genérica» (RUIZ SANJUÁN, C., Historia y sistema en Marx, op. cit., p. 38).

77 MARX, K.y ENGELS, F., El Capital, Libro III (trad. León Mames), SigloXXI Ed., Madrid, 2017, p. 933. 
de la personalidad de cada uno sea condición para el libre desarrollo de la de todos ${ }^{78}$. Y todo ello, claro está, implicará un programa lógico de superación de propiedad privada, familia y estado, reflejos de dicha escisión social, causas y a la vez consecuencias suyas, que solo tras su superación permitirán la reconciliación de las partes respecto a la totalidad y, por tanto, respecto de sí mismas: la reconciliación entre particularidad y universalidad. Y es que, como señalará Lukács, así nace la teoría crítica de Marx: «como continuación consecuente de aquello a lo que Hegel mismo había aspirado, pero sin conseguirlo concretamente», de tal forma que éste sí «realiza el programa de la filosofía de la historia de Hegel, aunque precisamente en una destrucción de la doctrina hegeliana» ${ }^{79}$.

78 MARX, K. y ENGELS, F., Manifiesto del Partido Comunista, Fundación Investigaciones Marxistas, Madrid, 2013, p. 77.

79 LUKÁCS, G., Historia y consciencia de clase, op. cit., p. 77 y 78. 


\section{Bibliografía}

ABENSOUR, M., La democracia contra el Estado (trad. Eduardo Rinesi), Ediciones Colihue, Buenos Aires, 1998 [1997].

ALVAREZ, E., El saber del hombre: Una introducción al pensamiento de Hegel, Editorial Trotta, Madrid, 2001.

ARAGÜÉS, R., Introducción a la Lógica de Hegel, Herder, Barcelona, 2021.

DOMÈNECH, A., El eclipse de la fraternidad: una revisión republicana de la tradición socialista, Madrid, Ediciones Akal, S. A., 2019 [2004].

DUQUE, F., Historia de la filosofia moderna: la era de la crítica, Ediciones Akal S.A., Madrid, 1998.

HEGEL, G. W. F., Enciclopedia de las ciencias filosóficas (Ed., Valls Plana), Abada Editores, Madrid, 2017 [1817].

—_, Principios de la Filosofia del Derecho (trad. Juan Luis Vermal), Edhasa, Barcelona, 1998 [1821].

LUKÁCS, M., Historia y consciencia de clase - Vol. I (trad. Manuel Sacristán), Ediciones Orbis, Barcelona, 1985 [1923].

MARCUSE, H., Razón y revolución: Hegel y el surgimiento de la teoría social (trad. Julieta Fombona de Sucre), Ediciones Altaya, Barcelona, 1994 [1941].

MARX, K., El Capital, Libro III (trad. León Mames), Siglo XXI Ed., Madrid, 2017.

—- Las luchas de clases en Francia de 1848 a 1850, Fundación Federico Engels, Madrid, 2015.

—_ El Manifiesto del Partido Comunista, Fundación de Investigaciones Marxistas, Madrid, 2013 [1848].

— Escritos de juventud, Fondo de Cultura Económica, México D.F., 1982.

MICHELET, J., Histoire de la Révolution Française [vol. I], Robert Laffont Ed., Paris, 1979.

PELCZYNSKI, Z. A., «La concepción hegeliana del Estado», Estudios sobre la «filosofía del Derecho» de Hegel, Centro de Estudios Constitucionales, Madrid, 1989.

PEREZ SOTO, C., Sobre la relación entre Hegely Marx, Revista Herramienta, disponible en: Sobre la relación entre Hegel y Marx (herramienta.com.ar).

PIPPIN, B. R., Hegel's realm of shadowes, The University of Chicago Press, Chicago, 2018.

RUDA, F., Hegel's Rabble: An investigation into Hegel's Philosophy of Right, Continuum Studies in Philosophy, London, 2011.

RUIZ SANJUÁN, G., Historia y sistema en Marx: hacia una teoría crítica del capitalismo, Siglo XXI Editores, Madrid, 2019.

SCHMITT, G., Hegel y Marx (Conferencia radical, 1931), disponible en: https://nochedelmundo. wordpress.com/2017/02/27/hegel-y-marx-por-carl-schmitt/amp/ 